\title{
Matérista
}

Revista Matéria, v. 11, n. 3, pp. 204 - 210, 2006

ISSN 1517-7076

http://www.materia.coppe.ufrj.br/sarra/artigos/artigo10791

\section{Tenacidade ao Entalhe por Impacto Charpy de Compósitos de Poliéster Reforçados com Fibras de Piaçava}

\author{
Sergio N. Monteiro ${ }^{a}$, Regina Coeli M. P. Aquino ${ }^{b}$, Felipe P. D. Lopes ${ }^{a}$, José Roberto M. d’Almeida ${ }^{c}$ \\ ${ }^{a}$ Universidade Estadual do Norte Fluminense, UENF, Laboratório de Materiais Avançados, LAMAV, Av. \\ Alberto Lamego, 2000, 28013-602, Campos dos Goytacazes, Brasil. \\ e-mail: sergio.neves@ig.com.br; felipeperisse@pop.com.br \\ ${ }^{\mathrm{b}}$ Centro Federal de Educação Tecnológica, CEFET-Campos, Campos dos Goytacazes, RJ , Brasil. \\ e-mail: araquino4@oi.com.br \\ c Departamento de Ciência dos Materiais e Metalurgia, Pontifícia Universidade Católica do Rio de Janeiro, \\ PUC-Rio, Rio de Janeiro, Brasil. \\ e-mail: dalmeida@dcmm.puc-rio.br
}

\section{RESUMO}

Fibras rígidas de piaçava do tipo Attalea funifera Mart vêm sendo recentemente investigadas como reforços efetivos para compósitos de matriz polimérica. Os trabalhos até agora realizados nestes compósitos mostraram um razoável aumento na resistência mecânica com a proporção de fibra. Como algumas possíveis aplicações para compósitos de piaçava demandariam resistência ao impacto, o objetivo do presente trabalho foi realizar um estudo da tenacidade ao entalhe, medida em pêndulo de impacto de compósitos com matriz poliéster reforçada com fibras rígidas e alinhadas de piaçava. Corpos de prova padronizados de compósitos com até $40 \%$ de fibras contínuas de piaçava foram avaliados por meio de ensaios Charpy e suas microestruturas na fratura investigadas através de microscopia eletrônica de varredura. Os resultados obtidos revelaram que compósitos de piaçava apresentam tenacidade ao entalhe comparativamente superior ao de outros compósitos poliméricos de fibras naturais.

Palavras chaves: Piaçava, compósitos, matriz poliéster, ensaio de impacto, tenacidade ao entalhe.

\section{Charpy Impact Notch Toughness of Piassava Fibers Reinforced Polyester Matrix Composites}

\begin{abstract}
Rigid piassava fibers of the specie Attalea funifera Mart have been recently investigated as effective reinforcements for polymeric composites. The works performed so far in these composites have shown a reasonable increase in the mechanical strength with the amount of fiber. Since some possible application for piassava composites would demand resistance to impact, the objective of the present work was to carry out a study on the notch toughness, measured by a pendulum hammer, of rigid and aligned piassava fiber reinforced polyester matrix composites. Standard specimens of composites with up to $40 \mathrm{wt}$ \% of continuous piassava fibers were evaluated by means of Charpy tests and their fracture microstructure investigated by scanning electron microscopy. The results obtain showed that piassava composites present a notch toughness behavior that is comparatively superior to that of other natural fiber reinforced polymeric composites.
\end{abstract}

Keywords: Piassava, composites, polyester matrix, impact testing, notch toughness.

\section{INTRODUÇÃO}

Compósitos reforçados com fibras naturais a base de celulose têm sido objeto de um grande número de publicações, hoje na casa de milhares, devido a vários fatores de interesse, tanto técnicos quanto econômicos. Dentre estes fatores destaca-se a natureza biodegradável e renovável das fibras vegetais, o que as torna ambientalmente corretas. Além disto, comparativamente com fibras sintéticas como as de vidro, carbono e aramida, as naturais lignocelulósicas podem ser bem mais baratas. Uma revisão geral destes 
compósitos com muitas referências importantes sobre seus diversos aspectos e fatores encontra-se no trabalho de Bledzki e Gassan [1].

Outro fator de grande relevância prática é a diversidade de fibras naturais existentes em nosso planeta [2, $\underline{3}$ ]. Muitas fibras são regularmente cultivadas como o algodão, linho, cânhamo, rami, sisal, juta, etc. Outras existem como subproduto de plantas com finalidade para alimento como o bagaço de cana, a casca do coco e o caule da bananeira. Um terceiro grupo corresponde àquelas fibras pouco conhecidas que só recentemente vêm sendo investigadas para aproveitamento como reforço de compósitos. Exemplos destas fibras são o curauá, a bucha e a piaçava. Esta última, em particular, tem sido objeto de inúmeros trabalhos [느므.

O aspecto que se destaca na fibra de piaçava da espécie Attalea funifera Mart, é a sua rigidez. Comparativamente com as outras fibras lignocelulósicas a piaçava é relativamente mais dura e não se amolda com facilidade a uma solicitação mecânica. Assim não é possível trançar fibras de piaçava para fazer fios ou cordas. Esta limitação é compensada pelo comprimento que estas fibras podem atingir na natureza de até 4 metros e diâmetros superiores a $1 \mathrm{~mm}$ [4]. Em princípio, é possível reforçar peças de compósitos, como placas e painéis para construção civil e mobiliário, utilizando, de maneira contínua e alinhada, o comprimento total das fibras de piaçava. Este reforço aumenta significativamente a resistência de compósitos poliméricos e pode ser utilizado até uma quantidade de $40 \%$ em peso de fibras de piaçava incorporadas na matriz [5], sem maiores problemas durante o processamento.

Por outro lado, as fibras de piaçava podem ser picadas em tamanhos menores para maior facilidade de incorporação em peças como capacete de ciclismo. Isto se deve ao fato do comprimento crítico medido para as fibras de piaçava ser de 1,5 cm [] ]. Em decorrência deste valor do comprimento crítico, a resistência ao cisalhamento da interface fibra de piaçava/resina poliéster é relativamente baixa, da ordem de 1,9 a 2,8 MPa. Esta conjugação de fatores pode ser favorável ao uso da fibra de piaçava em compósitos resistentes ao impacto, como será discutido a seguir.

Um compósito com elevada resistência ao cisalhamento interfacial, $\tau_{\mathrm{i}}$, ou seja com excelente ligação fibra/matriz, apresentará uma grande resistência mecânica, $\sigma_{\mathrm{m}}$, como um todo, devido à efetiva transferência de tensão da matriz para a fibra [7]. Entretanto, um elevado valor de $\tau_{\mathrm{i}}$ acarreta um compósito com baixa tenacidade já que pouca energia seria consumida durante a propagação das trincas na fratura. Estas trincas se propagam quase exclusivamente através da interface e junto à fibra que se constitui na região não-uniforme de maior concentração de tensões. Por outro lado, um compósito com baixo valor de $\tau_{\mathrm{i}}$ e uma ineficiente transferência de esforços da matriz para a fibra, terá relativamente maior energia. A razão para isto é que uma grande energia deve ser gasta no descolamento da fraca interface, ramificando a trinca e descolando a fibra da matriz através do mecanismo conhecido como pullout [7].

Tendo em vista estas considerações, existiria uma boa chance de que compósitos reforçados com fibra de piaçava apresentem boa tenacidade. Assim, o objetivo deste trabalho foi investigar a resistência ao impacto de corpos-de-prova de matriz poliéster com diferentes quantidades de reforço de fibras contínuas e alinhadas de piaçava.

\section{PROCEDIMENTO EXPERIMENTAL}

Fibras de piaçava do tipo Attalea funifera Mart, de ocorrência nativa no sul do estado da Bahia, foram obtidas como rejeito industrial de uma fábrica de vassouras localizada na cidade de Campos dos Goytacazes, Norte Fluminense. Estas fibras encontravam-se em estado natural com quantidade relativamente alta de umidade. As características estruturais e propriedades das fibras de piaçava investigadas neste trabalho foram apresentadas em outras publicações [ $[\underline{4}-\underline{6}, \underline{8}, \underline{9}]$.

Compósitos utilizando as fibras de piaçava, após serem secas ao ar livre, em quantidade de 0, 10, 20, 30 e 40 \% em peso foram preparados com matriz de resina poliéster do tipo ortoftálica da Dow Chemical. Placas dos compósitos foram fabricadas em um molde de aço com 152 x $122 \mathrm{~mm}$ e espessura de $10 \mathrm{~mm}$. Dentro do molde as fibras de piaçava foram mantidas alinhadas e ocupando todo o comprimento da direção com $122 \mathrm{~mm}$.

A resina ainda líquida, mas já acrescida de 0,5\% de catalisador à base de metil etil cetona, conforme indicado pelo fabricante, foi vertida sobre as fibras de piaçava dentro do molde. O compósito assim formado foi deixado curar por 24 horas na temperatura ambiente. Placas de cada compósito foram então cortadas, segundo a direção de alinhamento das fibras em barras medindo 120 × 12 × $10 \mathrm{~mm}$ que serviram como base para confecção de corpos de prova de ensaio de impacto Charpy, de acordo com a norma ASTM D256, conforme esquematicamente apresentado na Figura 1. 


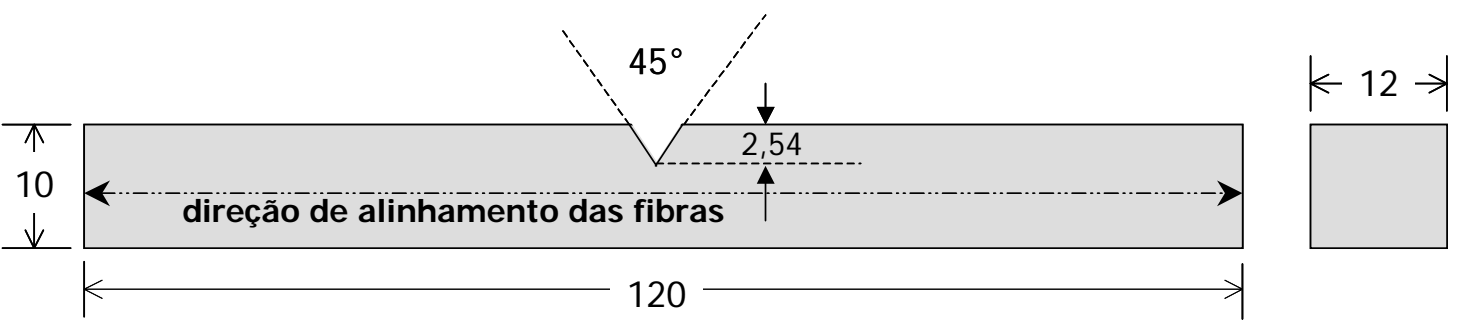

Figura 1: Esquema do corpo de prova utilizado para ensaio de impacto Charpy (dimensões em mm).

Para a confecção do entalhe com 2,54 mm de profundidade e ângulo de $45^{\circ}$ exigidos pela norma, Figura 1, Utilizou-se um entalhador manual da marca CEAST mod. Notchvas. Os corpos de prova foram ensaiados em um pendulo instrumentado, em configuração Charpy, da marca CEAST, mod. Resil Impactor pertencente ao Instituto de Macromoléculas da Universidade Federal do Rio de Janeiro, IMA/UFRJ. A energia de impacto, dependendo do martelo utilizado, variou de 5,5 a 21,6 J, para cada grupo de 8 corpos de prova associado às diferentes quantidades de fibras de piaçava nos compósitos.

A superfície de fratura dos corpos de prova, após o ensaio, foi analisada por microscopia eletrônica de varredura, MEV, em um equipamento Jeol, mod. JSM-460 LV do Programa de Engenharia Metalúrgica e de Materiais, PEMM/COPPE/UFRJ. Amostras cortadas da região de fratura foram metalizadas com ouro e observadas a 15 e $20 \mathrm{kV}$.

\section{RESULTADOS E DISCUSSÃO}

A Figura 2 apresenta a curva de variação da energia de impacto Charpy com a quantidade de fibra de piaçava no compósito.

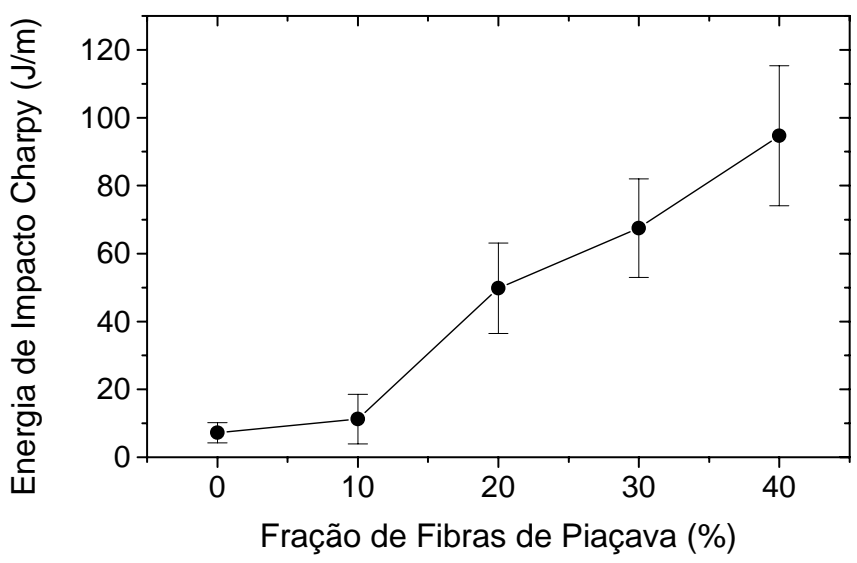

Figura 2: Energia de impacto Charpy em função da fração em peso de fibras de piaçava.

A curva da Figura 2 revela que a incorporação de fibra de piaçava na matriz de poliéster aumenta consideravelmente a tenacidade ao entalhe do compósito, medida pela energia de impacto Charpy. Este resultado, de um modo geral, já era esperado, uma vez que o reforço de fibras, tanto sintéticas [10] quanto naturais [11], reconhecidamente aumenta a energia de impacto de compósitos com matriz polimérica. O que surpreende nos valores obtidos para energia de impacto Charpy na Figura 2 são os níveis relativamente altos para frações de fibra de piaçava acima 10\%. Por exemplo, o nível de 94,7 \pm 20,6 J/m obtido para o compósito com $40 \%$ em peso de fibra de piaçava em matriz de poliéster é superior aos níveis de energia de impacto Izod mencionados para compósitos com matriz de polipropileno reforçada com diferentes fibras lignocelulósicas [11]. 
Como foi visto, a baixa resistência ao cisalhamento, $\tau_{\mathrm{i}}$, da interface entre a fibra de piaçava e a matriz de poliéster [6] contribui para uma ineficiente transferência de esforços da matriz para a fibra, acarretando maior energia absorvida no impacto [7]. Isto, em princípio, justificaria o nível superior obtido para a energia de impacto Charpy na Figura 2. Existe ainda outra razão para a elevada tenacidade conferida pelas fibras contínuas e alinhadas de piaçava na matriz de poliéster e que está associada à resistência ao dobramento destas fibras.

A Figura 3 apresenta uma foto do aspecto dos corpos de prova, com diferentes frações em peso de piaçava, após terem sido rompidos por impacto Charpy.

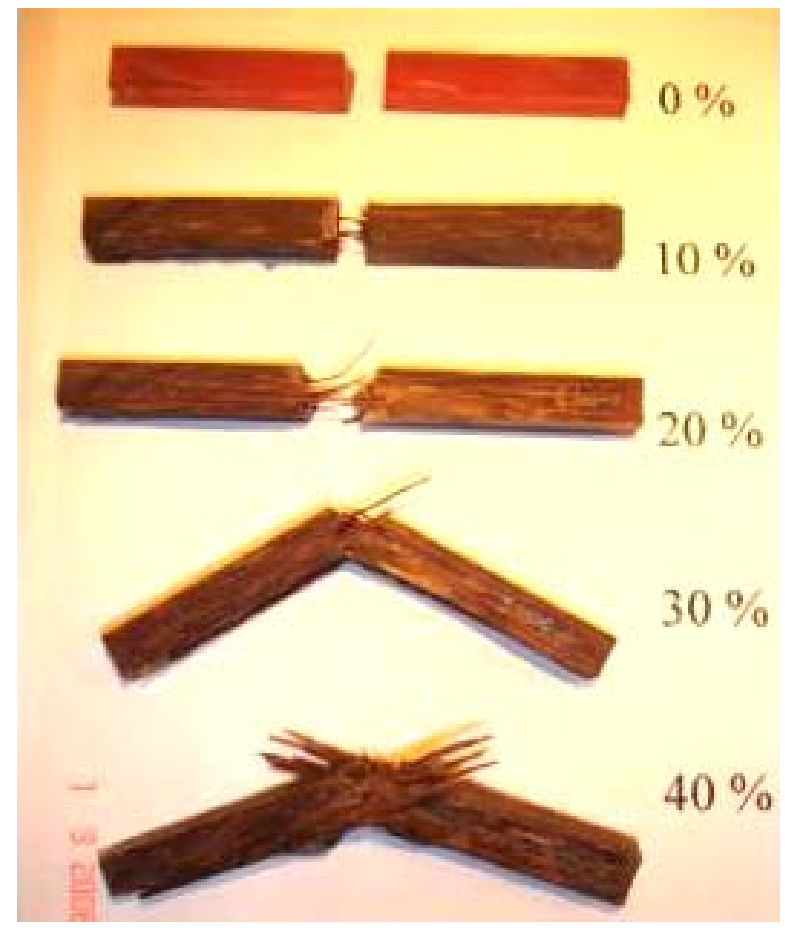

Figura 3: Aspecto dos corpos de prova rompidos por impacto Charpy.

Nota-se que até $20 \%$ de piaçava os corpos de prova foram totalmente separados em duas partes após o impacto. As pontas de fibra de piaçava que se destacam das superfícies rompidas, 10 e $20 \%$, evidenciam o papel de reforço destas fibras no impacto. Por outro lado, os compósitos com 30 e $40 \%$ de fibras de piaçava não romperam mesmo para impacto com o maior martelo Charpy disponível de 21,6 J. Na realidade, ao ocorrer o impacto, localmente a frágil matriz de poliéster foi fragmentada. Entretanto, as fibras de piaçava no local do impacto não se romperam, mas se dobraram a tal ponto que permitiram às extremidades do corpo de prova se soltarem dos respectivos batentes de apoio no equipamento. Ou seja, as fibras de piaçava foram curvadas em torno da superfície da cabeça do martelo Charpy sem se romperem e sem se separarem, Figura 3 , das extremidades onde a matriz de poliéster permaneceu intacta. Assim, o corpo de prova assumiu um novo formato em U, permitindo que fosse projetado, após o impacto, praticamente sem interferência dos apoios de suas extremidades.

Obviamente que os resultados da energia de impacto Charpy nestes casos, 30 e 40 \% na Figura 3, não podem ser comparados com outros resultados nos quais o corpo de prova é totalmente rompido em duas partes. Mesmo assim, tem-se uma indicação da elevada tenacidade conferida ao compósito pela fibra de piaçava devido à sua dificuldade em romper-se sob cargas impactantes.

A análise da superfície de fratura resultante do impacto Charpy permitiu acrescentar informações ao desempenho dos compósitos de matriz poliéster reforçados com fibras de piaçava. Inicialmente será analisada a superfície de fratura por impacto da pura resina de poliéster para então servir de comparação com os compósitos reforçados com fibra de piaçava. Deve ser lembrado que a fratura completa somente ocorreu para compósitos reforçados com até $20 \%$ de fibras de piaçava. Assim, a análise da superfície de fratura ficou limitada a estes compósitos.

A Figura 4 apresenta, com baixo aumento, a fratura de um corpo de prova com $0 \%$ de fibra, isto é, pura resina poliéster. 


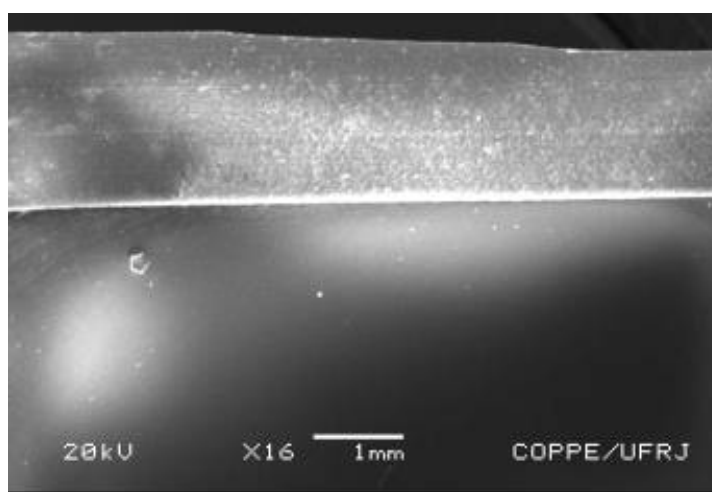

Figura 4: Micrografia da superfície de fratura do corpo de prova com 0 \% de fibra.

Na parte superior da Figura 4 tem-se uma banda mais clara e rugosa correspondente ao entalhe feito por ferramenta especial. A parte inferior mais escura, lisa e brilhante corresponde à superfície de fratura da resina poliéster após o impacto. $\mathrm{O}$ aspecto liso e homogêneo desta fratura está associado à natureza frágil que é característica da baixa tenacidade dos polímeros [12].

A Figura 5 apresenta, com maior aumento, detalhes da superfície de fratura apresentada na Figura 4. Observam-se estrias correspondentes às marcas e degraus deixados pela única trinca responsável pela ruptura do corpo de prova e que foi nucleada a partir do entalhe. Esta trinca também deixou marcas envolvendo pequenas cavidades existentes no material, possivelmente resultante da porosidade introduzida durante o processamento.

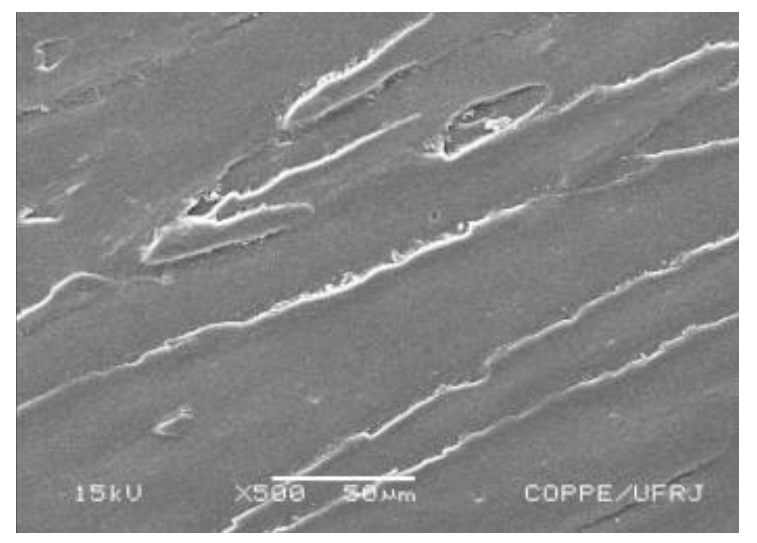

Figura 5: Detalhe da superfície de fratura da Figura 4.

A Figura 6 apresenta, com baixo aumento, a fratura de um corpo de prova com 20\% em peso de fibra de piaçava. Na parte superior desta figura, a faixa horizontal com 2,54 mm de espessura, conforme a norma, corresponde ao entalhe feito com ferramenta especial. Notam-se na superfície do entalhe, marcas arredondadas das fibras inseridas na matriz de poliéster e que foram seccionadas pela ferramenta durante a confecção do entalhe. Na parte inferior da Figura 6, tem-se a superfície de fratura na qual se verifica que algumas fibras foram rompidas rentes e outras se salientando em relação à matriz de poliéster, esta com aspecto liso, como nas Figuras 4 e 5.

Observam-se também na Figura 6 orifícios associados ao total descolamento de fibras que provavelmente ficaram presas na outra parte do corpo de prova fraturado. Isto demonstra que a tensão interfacial fibra/matriz é relativamente fraca com já havia sido constatado [6] ]. Este fato é uma das razões para o efetivo aumento da tenacidade do compósito, causado pelo reforço de fibras longas e alinhadas de piaçava. 


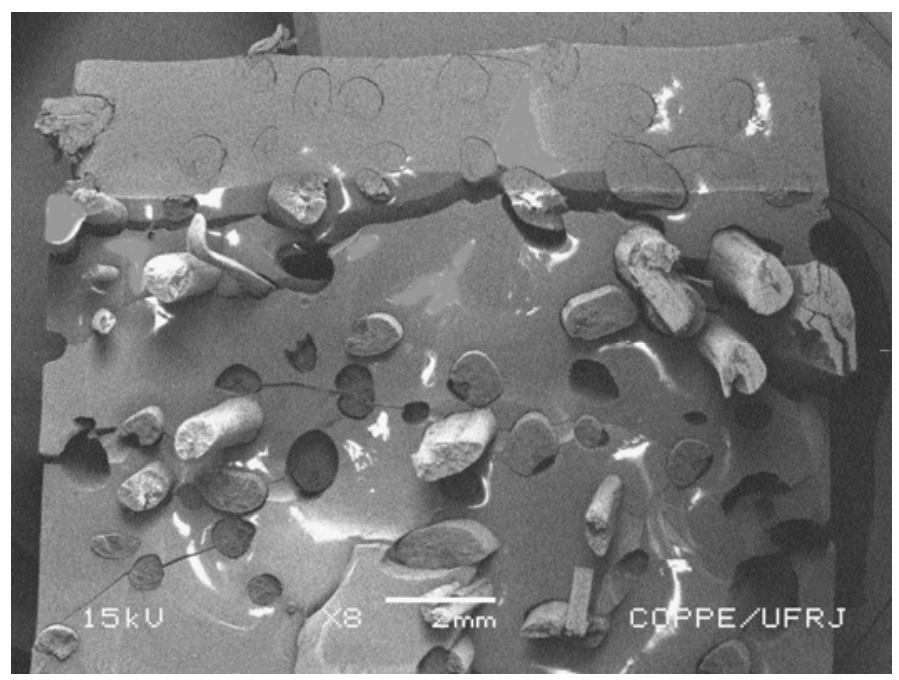

Figura 6: Micrografia da superfície de fratura do corpo de prova com 20\% de fibra.

A Figura 7 apresenta, com maior aumento, detalhe da interface entre uma fibra, região bem rugosa na parte baixo/esquerda, e a matriz, na parte alto/direita, da micrografia. Deve ser notado o descolamento da fibra em relação à matriz devido à baixa tensão interfacial [6]. Também é importante observar que uma outra trinca, perpendicular à superfície de fratura, divide a matriz em duas partes. Estes aspectos corroboram a maior energia de impacto dos compósitos devido à participação das fibras de piaçava. Ou seja, um grande número de trincas acarreta elevada área superficial na fratura associada a uma energia relativamente maior.

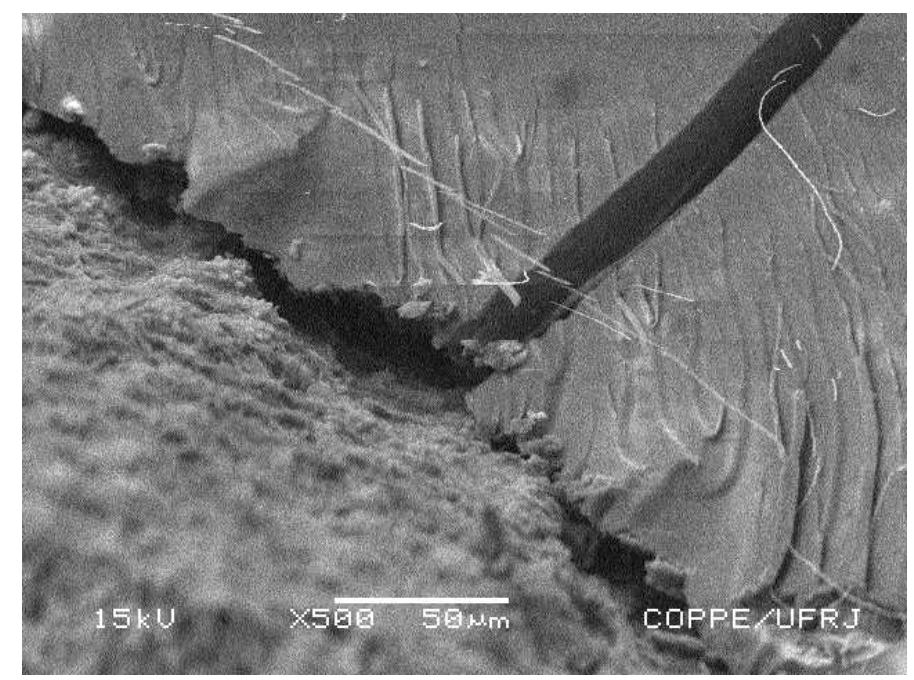

Figura 7: Detalhe da micrografia da Figura 6.

Finalmente, é importante reiterar o fato de que, no caso dos compósitos com 30 e $40 \%$ em peso de fibras de piaçava, não foi possível analisar a microestrutura da superfície de fratura pelo simples fato de não ter ocorrido separação total do corpo de prova. Nestas condições, a grande capacidade de deformação das próprias fibras de piaçava, como já havia sido discutido, contribui para a elevada tenacidade registrada nos compósitos com frações maiores que $20 \%$.

\section{CONCLUSÕES}

Compósitos de matriz poliéster reforçada com fibras contínuas e alinhadas de piaçava apresentam um elevado aumento na tenacidade ao entalhe, medida pela energia de impacto Charpy, quanto maior for a fração incorporada, até pelo menos $40 \%$ em peso de fibra de piaçava. 
Parte deste aumento na tenacidade ao entalhe é devido à baixa tensão interfacial, ou seja, baixa resistência ao cisalhamento da interface entre a matriz de poliéster e as fibras de piaçava, o que acarreta maior energia associada ao descolamento da fibra e ramificações da trinca.

Para frações de fibra de piaçava superiores a $20 \%$, o aumento na tenacidade ao entalhe é também devido à grande energia despendida em se dobrar as fibras que não conseguem ser rompidas dentro dos procedimentos do ensaio de Charpy.

\section{AGRADECIMENTOS}

Os autores agradecem o apoio do CNPq, CAPES e FAPERJ. É também motivo de agradecimento a colaboração de Márcia Soares Sader e Felipe Sabatino Gonçalves Vieira bem como a permissão para utilização do microscópio eletrônico de varredura do PEMM da COPPE/UFRJ. Um especial agradecimento é devido à Profa. Elen Beatriz A. V. Pacheco do IMA/UFRJ.

\section{REFERÊNCIAS}

[1] BLEDZKI, A.K., GASSAN, J., “Composites Reinforced with Cellulose-Based Fibres”, Progress in Polymer Science, v. 24, pp. 221-274, 1999.

[2] LEÃO, A.L., CARVALHO, F.X., FROLLIN, E., Lignocellulosic - Plastic Composites, São Paulo, Brasil: USP \& UNESP, 1997.

[3] D’ALMEIDA, J.R.M., MONTEIRO, S.N., “Compósitos Reforçados por Fibras Naturais - Oportunidades e Desafios”, In: 58 Congresso Anual da ABM, pp. 1725-1734, Rio de Janeiro, Brasil, 2003.

[4] AQUINO, R.C.M.P., D’ALMEIDA, J.R.M., MONTEIRO, S.N., "Flexural Mechanical Porperties of Piassava Fibers (Attalea funifera)-Resin Matrix Composites”, Journal of Materials Science Letters, v. 20, pp.1017-1019, 2001.

[5] AQUINO, R.C.M.P., Desenvolvimento de Compósitos de Fibras de Piaçava da Espécie Attalea funifera Mart e Matriz de Resina Poliéster, Tese de D.Sc., UENF, Campos dos Goytacazes, RJ, Brasil, 2005.

[6] AQUINO, R.C.M.P., MONTEIRO, S.N., D’ALMEIDA, J.R.M., "Evaluation of the Critical Fiber Length of Piassava (Attalea funifera) Fibers using the Pullout Test”, Journal of Materials Science Letters, v. 22, pp. 1495-1497, 2003.

[7] YUE, C.Y., LOOI, H.C, QUEK, M.Y, “Assessment of Fibre-Matrix Adhesion and Interfacial Properties Using the Pullout Test”, International Journal of Adhesion and Adhesives, v. 15, pp.73-80, 1995.

[8] MONTEIRO, S. N., D’ALMEIDA, J.R.M., AQUINO, R.C.M.P., “Análise do Compósito Piaçava-Resina Poliéster como Substitutivo da Madeira”, In: 60 Congresso Anual da ABM, pp. 1484-1492, Belo Horizonte, Brasil, 2005.

[9] DE DEUS, J.F., MONTEIRO, S.N., D’ALMEIDA, J.R.M., “Effect of Drying, Molding Pressure, and Strain Rate on the Flexural Mechanical Behavior of Piassava (Attalea funifera Mart) Fiber-Polyester Composites”, Polymer Testing, v. 24, pp. 750-755, 2005.

[10] FU, S.Y., LAUKE, B., MÄDER, E., Hu, X., YUE C.Y., "Fracture Resistance of Short-Glass-FiberReinforced and Short-Carbon-Fiber-Reinforced Poly-propylene under Charpy Impact Load and its Dependence on Processing”, Journal of Materials Processing Technologies, v. 89/90, pp. 501-507, 1999.

[11] LEÃO, A.L., CARASCHI, J.C., TAN, I.H., "Curaua fiber - A Tropical Natural Fibers from Amazon Potential and Application in Composites”, Natural Polymers and Agrofibers Composites, pp. 257272, São Paulo, Brasil, USP \& UNESP, 2000.

[12] HERTZBERG, R.W., Deformation and Fracture Mechanics of Engineering Materials, $4^{\mathrm{a}}$ Ed., Nova York, EUA, John Wiley \& Sons, 1996. 